\title{
Visceral Artery Ischemia
}

National Cancer Institute

\section{Source}

National Cancer Institute. Visceral Artery Ischemia. NCI Thesaurus. Code C78712.

Decreased blood supply to the small or large intestine due to narrowing or blockage of a visceral (mesenteric) artery. The ischemia results to the damage of the intestinal tissues. It may be chronic, caused by atherosclerosis or acute, secondary to the formation of a thrombus or embolus in the mesenteric arterial lumen. In chronic ischemia, patients present with abdominal pain manifested in a short time after a meal and weight loss. In acute ischemia, patients present with sudden and acute abdominal pain, nausea and vomiting, and blood in the stool. 